\title{
NOTES ON THE SYSTEM OF CRYSTALLIZATION AND PROPER CUTTING OF THE SYNTHETIC CORUNDUM GEMS. ${ }^{1}$
}

By Frank B. Wade, Shortridge High School, Indianapolis, Ind.

It is with some hesitation that I am attempting to present before the Physical Science Section of the Indiana Academy of Science a paper upon so technical a subject as the system of crystallization of the synthetic corundum gems, when my study of them has been but the recreation of one whose serious work lies in another direction.

It was while attempting to learn how to produce the best possible results in the way of richness and depth of color in cutting synthetic ruby that I made a study of the crystalline form of the rough ruby boules. The best lapidaries, in cutting natural ruby, long ago learned that, to produce the deepest and richest color it was necessary to lay the table of the cut stone parallel with the basal planes of the natural hexagonal crystal. Fortunately this method of cutting usually gave also the largest possible cut stone from the rough material, as the natural ruby has a tabular habit, with the greatest diameters parallel to the basal planes of the hexagonal prism.

Now-although the rough boule of synthetic ruby has the appearance of an amorphous mass - it is in reality crystalline, in fact a single crystal. Hence in cutting it proper regard should be had for its optical properties if the best results are to be obtained. The boules, however, although single crystals, have no well defined crystal faces or cleavages to reveal the system of crystallization orthe direction of the optical axes.

It was in the endeavor to work out methods of determining these matters that I began a study of rough boules. I first studied the literature that was available upon the subject of artificial corundum gems, and for the sake of refreshing your memory in this direction I will briefly review that part of it which leads toward the subject of this paper.

The earlier workers attempted to obtain rubies by the fusion of alumina, either in glass or porcelain furnaces or by means of the oxyhydrogen blowpipe. M. Gaudin, in 183\%, using the oxyhydrogen blowpipe to produce fusion, got tiny crystals of ruby when the melt was slowly cooled. These crystals, like those of nature. were in the hexagonal system, as shown by their external form. St. Clair de Ville and Caron produced rubies by fusion of alumina

1 Proceedings of Indiana Açadeny of Science, page 164. 
mixed with a little chromium oxide and, on one occasion they got both rubies and sapphires in the same crucible. These were very minute and had the usual crystal form of the natural stones. Fremy, by means of a high temperature continued for eight days, got rubies of the weight of one-third karat each. These also were regular crystals. No success was had by any of these earlier workers in obtaining rubies of commercial size.

About 1885 there began to come on the market, from Geneva, Switzerland, it is now said, some rubies which at first were sold as natural stones, but which, it developed later, were made by fusing together small natural rubies by means of the oxyhydrogen blowpipe. These ribies were generally bubbly, and the bubbles, unlike those in natural rubies, were spherical. There were also other signs by means of which the artificial character of these socalled "reconstructed" rubies might be detected. They were generally too low in specific gravity, probably owing to their bubbly character, and the color was a bit unnatural to the eye of an expert. They were, however, crystallized alumina. I have not had the opportunity of examining any of the drops thus produced while in the uncut condition, so that I am unable to speak in regard to their crystal structure. The cut stones are feebly double refracting and show dichroism like the natural rubies.

It was not long before the use of small natural rubies was discontinued and pure alumina mixed with a little chromium oxide was substituted. It was in 1904 that Verneuil published his method of producing true synthetic rubies by heating the above mixture in the flame of the oxyhydrogen blowpipe. The method employed by him in introducing the powdered material was exceedingly ingenious. A receptacle with a sieve bottom was constantly tapped by a mechanical tapper and the dust fell into the stream of oxygen and passed with it through the flame, which was directed vertically downward upon a support below. Upon this support the boule grew; first the slender stem, then, with proper manipulation of the flame the wider and wider dome, until, in some cases, the boule weighed over one hundred karats. The crystal character of these boules and of the blue and pink and white and yellow ones which later came to be made, forms the principal subject of this. paper.

The blue color was obtained only after long study and experimentation on the part of Verneuil and an American assistant, Mr. I. H. Levin. They found that the attempt to blend cobalt as a colorant failed, the cobalt volatilizing or else floating out when the 
boule cooled. Picard, in 1907, and Louis Paris, in 1908, succeeded in getting boules of a fine blue color by blending magnesia or lime with the alumina and adding cobalt. They were. however, not true sapphires. Some of these boules were sent to a friend of mine, an enthusiastic gem collector, Mr. Wm. H. Huse, of Manchester, $N$. H., and at his request I tested them and found that they were too low in specific gravity, too soft, and their system of crystallization was the regular or cubic system. They were singly refracting and showed no dichroism. They were, in fact, artificial spinels. Their color also was of too piercing a blue. This was afterwards remedied by adding a trace of chromium oxide, but then the color as seen by artificial light was unnatural.

In January, 1910, Verneuil and Levin succeeded in obtaining true sapphires by adding to 98 per cent of alumina 2 per cent of a mixture of ferric oxide and titanium oxide and keeping the boule in a reducing atmosphere. A paper in regard to these boules was read by Verneuil in 1910 before the French Academy. It quoted M. Wyrouboff, who examined them before they were submitted to the Academy. He said of them: They take the form of a single crystal which is uniaxial, optically negative and little birefractive, consequently having all the optical properties of the natural sapphires. Furthermore, their composition and crystalline construction must evidently lead to the conclusion that these stones are in every other respect identical with the natural sapphires. They even show the parti-colored effects like the natural stones."

In connection with this report of Wyrouboff I will quote here the report of Batuer, the great German gem expert, on the synthetic ruby boules. In a paper read before the German Chemical Society of Frankfort, A. M. Bauer says: "The ruby bulb, in spite of its round shape, shows a true crystalline formation. In specific weight, in hardness, as well as in all the optical properties, it is identical with the natural stone; in color and brilliancy it vies with the best specimens from the Orient."

Some of the new blue sapphires were sent to this country and were submitted to Prof. Alfred Moses of Columbia University, who says: "The chemical analysis show's the material submitted to be nearly pure alumina with, however, a measurable quantity of titanic oxide. The crystallographic and optical tests show that the material submitted is crystallized and that the cone by all tests is one homogeneous faceless (anhedral) crystal. The crystalline, optical and other characteristics determined are close- 
ly those of natural sapphire. In the absence of natural faces or cleavages the crystalline system, as determined by the optical tests, may be either hexagonal or tetragonal. The parting figures point to the hexagonal system. Any two natural substances which were as nearly identical in chemical and crystallographic characters as the specimens submitted and natural sapphires would be called identical. The difference is one of origin."

While expert mineralogists are agreed thàt these synthetic products are identical with the natural in all their properties, yet the synthetic stones may in nearly every case be distinguished from the natural by one who is trained in seeking minute differences due to the difference in origin. As is now well known in the trade, the synthetic stones frequently contain bubbles which are always round or rounding in form. Natural corundum gems also frequently contain bubbles, but these are always bounded by crystal planes and are hence angular in appearance. Lacking the bubbles strix may be seen in the synthetic stones, especially in the 'rubies, and these striæ, while parallel like those so often seen in natural stones, are, unlike the latter, not straight but curving. The color, too, in the case of the ruby, is not quite equal to that of the best natural stones, although in this respect I hope to show that the defect is probably due to improper cutting rather than to any real difference in the material. The synthetic rubies seem also to interfere with the passage of light through them to a greater extent than the natural stones when the latter are clear. This results in a sort of general illumination of the interior of the stone. One might say that the material was not optically a vacuum and that the Tyndall effect was produced. The flashes of light produced by total reflection from the rear facets of the stone are therefore seen against a background of faintly illuminated material instead of against a dark background, as in the natural ruby. This detracts from the beauty of the synthetic ruby somewhat, and it is this phenomenon I believe which enables an expert to tell by inspection without the aid of a lens whether a stone is a natural or a synthetic ruby. Some experts have claimed that they could tell by the touch alone whether a stone was a synthetic or a natural one. This difference I believe to be due to the very hasty manner in which the synthetic stones are cut. They are cut abroad so cheaply that they can be sold in America for less than the price per carat charged for cutting alone by the American lapidary. It is thus probably the inferior surface finish of the synthetic stone that reveals itself to the trained touch of the ex- 
pert. I have carefully polished a specimen of synthetic ruby to determine this point, and while I can feel a difference between the synthetic stone of commerce and the natural stone, I am unable to distinguish any difference between my finely polished synthetic stone and a natural one.

I have shown that gem experts have decided that the boules of synthetic corundum gems are single crystals and that they crystallize either in the hexagonal or in the tetragonal system. Professor Moses of Columbia University said also that the parting figures suggested the hexagonal system. The experts also said that the crystals were anhedral or faceless. I wish now to add some evidence from my study of them that indicates that the boules are not altogether faceless, and then to advance evidence along two different lines to prove that the crystals are of the hexagonal system, as was indicated by the parting figures.

Observation of a considerable number of the boules shows that there is a flattening on one side of nearly every boule, and an optical study of the boules shows that this flattening is nearly parallel to the basal planes of the crystal. Viewed with the dichroiscope perpendicularly to the flattened place there is no dichroism. The depth of color, too, is greatest when viewed in this direction, and that would be true of natural ruby when viewed perpendicularly to the basal planes of the hexagonal prism. On grinding the surface parallel to the flattened place a slightly pearly effect is seen, and this surface thus produced is more diffictlt to polish than a surface that cuts across the grain in any other direction. This is generally true when working parallel to the cleavage of a natural crystal, and thus indicates that the flattened place on the boule represents the base of the prism. On this flattened face markings appear, indicating distortion of the edges of the layers of the material. There is a drawing down and curving of the edges of the layers as they cross the basal plane as though some force had distorted the layers as they arrived. These markings go far down toward the stem of the boule, indicating that the direction of crystallization is early determined. In a few boules the flattening is absent, and then I have found that the optical axis lies up and down the boule and that the top of the boule is flatter than in the other type. In such boules there is also evident a tenciency toward forming a hexagonal prism with faces and angles roughly apparent. Where the flattening occurs on the side of the boule, which is the ustal case, it does not form a perfect plane, being apparently interfered with--perhaps by the surface tension 
of the semi-plastic mass. The longest horizontal diameter of the boules (they are made with the stem of the pear acting as a vertical support) is invariably parallel to the flattened face. On the side of the boule opposite to the flattened face there is sometimes another and smaller flattened face approximately parallel to the first. This, too, shows evidence of distortion of the lines representing the edges of the strata of accretion.

From what has been advanced in regard to these imperfectly developed basal faces I think that the term anhedral as used to describe the boule should be qualified. The boules are nearly anhedral, but not quite so. The forces of crystallization succeeded in forming a single crystal in spite of the adverse forces acting upon the boule, but they were unable to face up the crystal except imperfectly, as has been described.

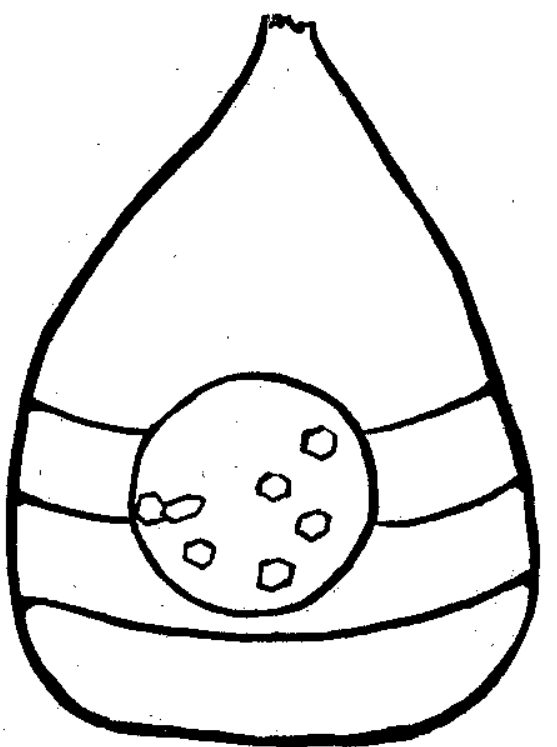

Figure 1A. Rutby Viewed on Fitat Side.

I will now pass to my next topic and offer evidence of the hexagonal character of the boules. On examining the flattened surfaces described above, by means of a compound microscope with a magnification of several hundred diameters, I found that by proper focusing I was able to trace the outlines of minute crystals which formed a species of frost work upon the surface of the boule. These crystals were all of similar orientation, and their orientation was nearly that of the boule itself. When viewed 
perpendicularly to the flattened place on the boule the minute crystals had hexagonal forms (Figures $I \mathrm{a}$ and $\mathrm{b}$ ). When viewed at right angles to the basal plane of the boule rectangular figures representing the edges of hexagonal plates were seen (Figures II $a$ and $b)$. The evident hexagonal form of these minute components of the crystal and their common orientation would seem to prove the hexagonal character of the boule on a crystallographic basis independently of the optical evidence.

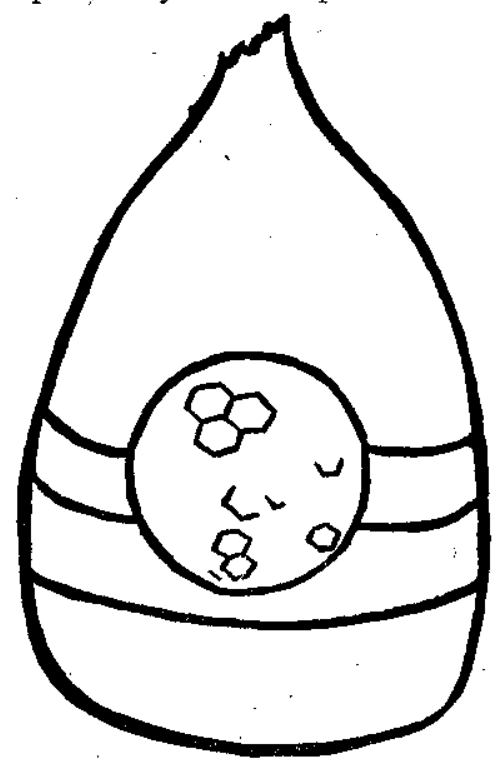

Figure 1B. Yellow Sapphire Viewed on Flattened Side.

I find also that by examining fractured surfaces of ruby boules with similar magnification (i. e., several hundred diameters) I can find sharp hexagonal cavities out of which hexagonal plates have been torn by the fracture as though there had been a species of molecular cleavage. This, too, would seem to confirm from a crystallographic basis the hexagonal structure of the boule.

As further evidence of this structure $I$ find that in the case of a cabochon cut (smooth, convex upper surface) ruby which I myself cut from a fragment of a boule, I can plainly see a six-pointed star when viewed in direct sunlight or even when seen by the light of a single candle. This star effect is due to the presence in the material of microscopic bubbles, which produce somewhat the same effect as is produced by dust particles in a beam of light crossing a darkened room. The six-pointed character of the star 
plainly indicates that the material has the hexagonal arrangement, as a tetragonal crystal under similar conditions would produce a cross rather than a six-pointed star.

Having, as I believe, sufficiently shown that-as would be expected from its resemblance to the corundum gems of naturethe artificial gem corundum forms single hexagonal crystals, I will now briefly indicate how practical advantage may be taken of this fact in the cutting of fine gems. The lapidary may now by mere inspection of the boule determine (by finding the flattened side) the location of the basal planes of the crystal. "He should

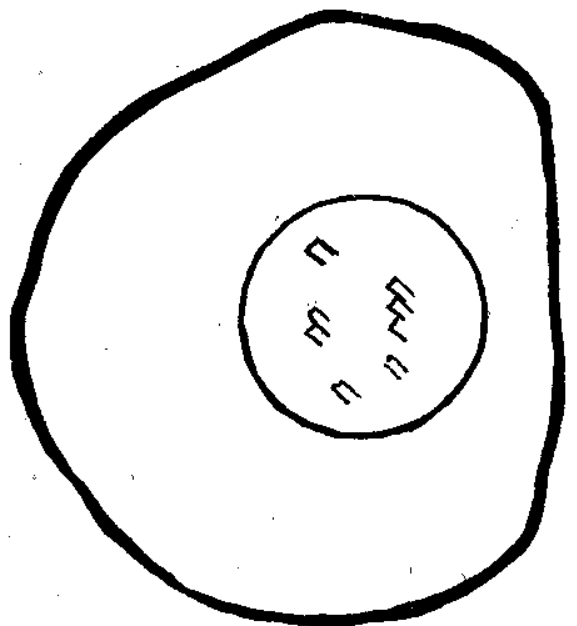

Figure 2A. Yellow SAPphire Viewed on Top.

then cut the stone so that the finished product will have the table (large top facet) parallel to the flattened place on the boule (i. e., parallel to the basal planes of the crystal). Now a study of hundreds of cut stones of the synthetic type has shown that rarely if ever is one cut in accordance with this rule. Hence the fine deep color of the best specimens, of natural ruby, for example, is almost never equalled in the synthetic stones. By roughing out a ruby to nearly its finished form myself and then having a skilled lapidary facet it I have obtained a cut stone which I believe to be as deep and pure in color as the best of the natural stones. The synthetic stones of commerce seem to be cut as the boules break, and $I$ find by opening botles myself that they nearly always break in such a direction that to cut the finished stone as it should be cut would waste two-thirds of the material; that is, a much greater spread in the finished stone may be had by cutting it as 
it breaks rather than by cutting it as it should be cut to obtain the best color. I have tried to gutide the break by using the natural edge of a diamond crystal so as to split the boule to favor the correct cutting, but the crack tends to turn around to the other side of the boule. I suspect that this is due to the following fact: As was said above, the flattened face of the boule is almost always parallel to the longer axis of the oval cross-section of the boule. Now natural ruby tends to cleave parallel to the basal planes, but only feebly so. The boules are under internal strain, somewhat

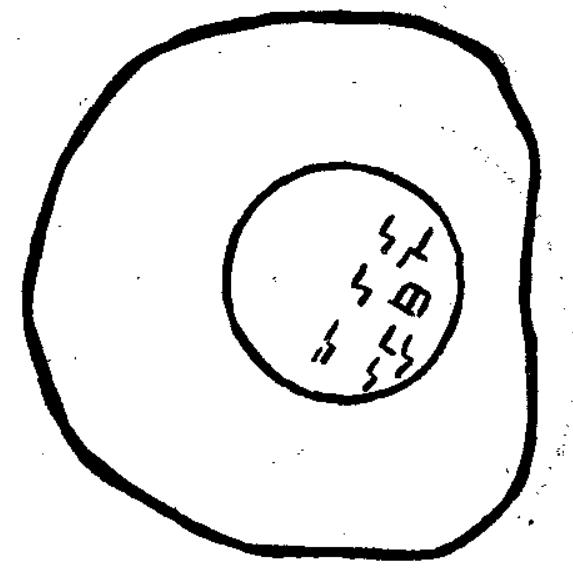

Figure 2B. Ruby Viewed on Top.

as Prince Rupert's drops are, and when the surface of the boule is abraded even slightly, cracking follows and the strain is relieved. By cracking along the length of the boule at right angles to the plane of the flattened surface a smaller cross-section is made than would be made were the boule to split parallel to the basal planes. The natural cleavage is so feeble that I suspect the split follows the other direction as a line of least resistance. At any rate the boules split contrary to the natural cleavage and disadvantageously as regards cutting to produce the best color. By slitting with the diamond saw after the break has occurred the practical lapidary can still utilize the material advantageously and, keeping run of the position of the basal planes by means of the flattened place, can indicate in some manner upon the surfaces of the fragments where the table of the finished stone should be laid.

By giving due attention to this matter, synthetic rubies and sapphires equal in depth and purity of color to the fine stones 
of nature can be produced. They will necessarily be sold at a higher price than most of those now on the market, but they will be worth more and should find a moderately large market among people of taste and discernment who have always loved to look upon fine natural sapphires and rubies, but who were unable to possess them at the prices commanded by the rare natural product.

\section{A USEFUL LANTERN SLIDE SERVICE.}

For ten years and more Cornell College, Iowa, has maintained as a special form of University Extension a lantern slide service in geology and physiography for the schools and colleges of the middle West. The college collection in these subjects numbers upwards of 4,000 slides and from it there have been selected 1,500 slides for this service. The following subjects are illustrated each with a set of fifty slides:

Weathering and Rock Sculpture (2).

Rivers, their Works and Ways (2).

The Travels of Water Underground (2).

The Arid Cycle.

Glaciers (2).

The Sea and Its Shores (2).

Earthquakes.

Movements of the Earth's Crust and Mountains.

Volcanoes.

Lakes, Their Origin and Life History.

The Grand Canyon of the Colorado, and other Canyons.

Niagara, and other Waterfalls.

The Desert and Its Flora.

Land Sculpture by Glaciers.

The Great Ice Age in North America.

Yosemite.

Norway, Its Fjords and Fjelds.

The World's Greatest Ice Fields.

Land Forms of Iowa.

Vesuvius and Its Burried Cities.

Mt. Pelle.

The Hawaiian Volcanoes.

Lava Plateaus of the Northwestern United States, Iceland, and India.

Yellowstone Park and Its Decadent Vulcanism.

Prehistoric Reptiles and Mammals.

Early Man.

Each set of slides is accompanied by a type-written manual explaining the features of the slides and suggesting their uses as class problems for sight-solution. The demand for the slides is such that it is necessary to order them at least one week in advance. All correspondence on the subject may be addressed to Prof. W. H. Norton, Mt. Vernon, Iowa. 